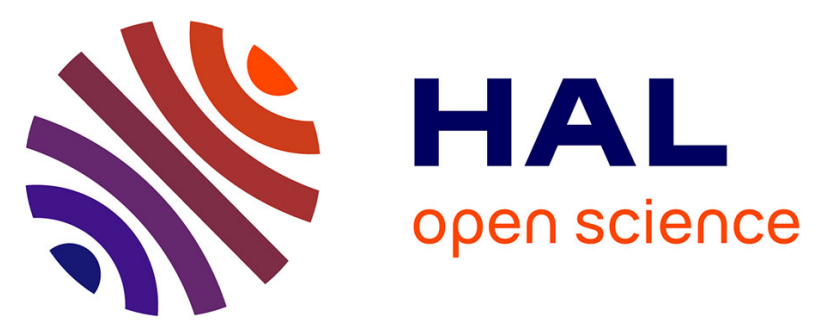

\title{
Optical response and SERS properties of individual large scale supracrystals made of small silver nanocrystals
}

Pierre Aubertin, Mohamed Ali Ben Aissa, Noureddine Raouafi, Suzanne Joiret, Alexa Courty, Emmanuel Maisonhaute

\section{- To cite this version:}

Pierre Aubertin, Mohamed Ali Ben Aissa, Noureddine Raouafi, Suzanne Joiret, Alexa Courty, et al.. Optical response and SERS properties of individual large scale supracrystals made of small silver nanocrystals. Nano Research, 2015, 8 (5), pp.1615-1626. 10.1007/s12274-014-0650-5 . hal-01298105

\section{HAL Id: hal-01298105 \\ https://hal.sorbonne-universite.fr/hal-01298105}

Submitted on 5 Apr 2016

HAL is a multi-disciplinary open access archive for the deposit and dissemination of scientific research documents, whether they are published or not. The documents may come from teaching and research institutions in France or abroad, or from public or private research centers.
L'archive ouverte pluridisciplinaire HAL, est destinée au dépôt et à la diffusion de documents scientifiques de niveau recherche, publiés ou non, émanant des établissements d'enseignement et de recherche français ou étrangers, des laboratoires publics ou privés. 


\section{Graphical Table of Content}

Small silver nanocrystals self-organized at 3D present exceptional optical properties and intense SERS responses.

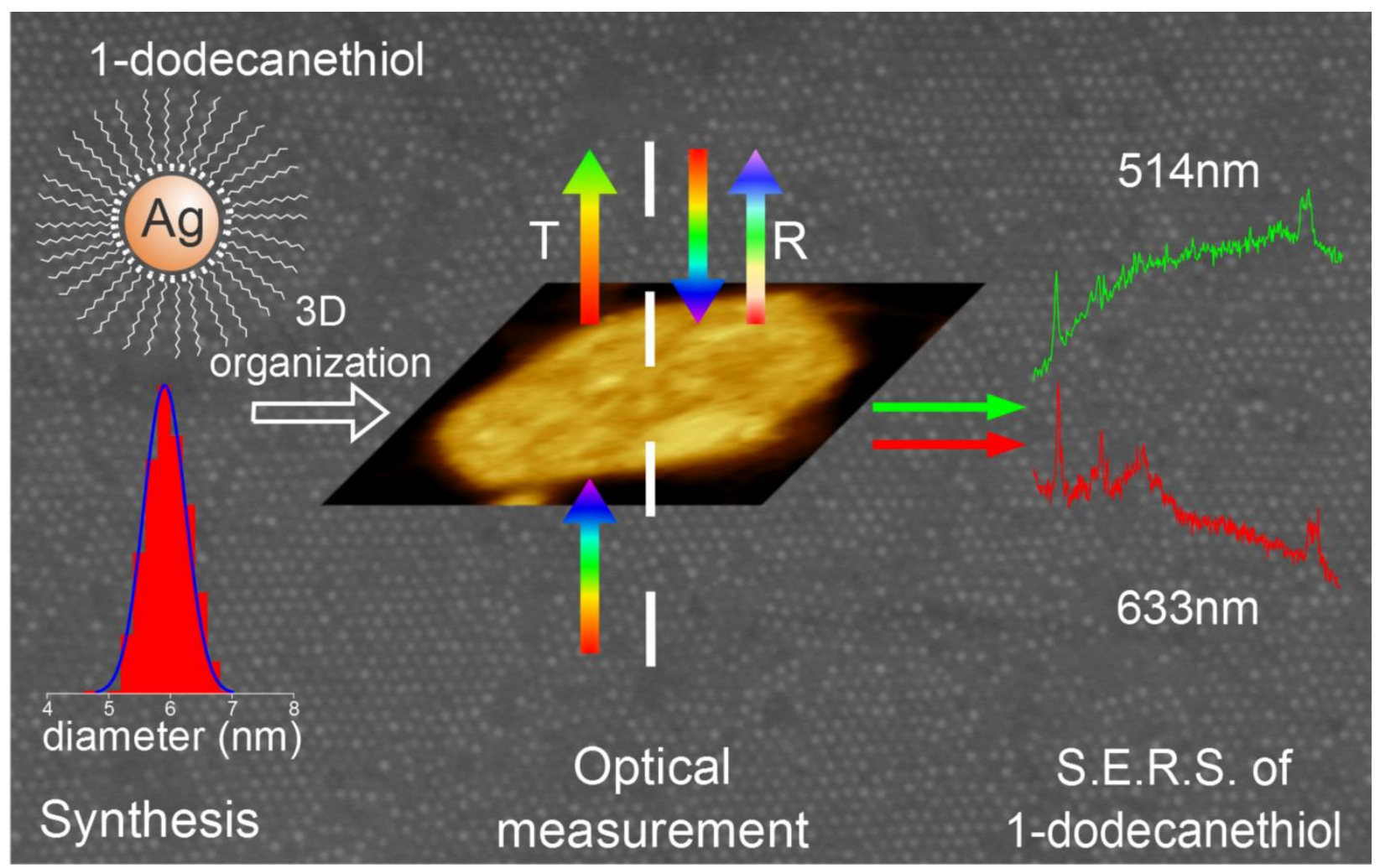




\section{Optical Response and SERS Properties of}

\section{Individual Large Scale Supracrystals Made of}

\section{Small Silver Nanocrystals.}

Pierre Aubertin ${ }^{\dagger,}$, Mohamed. A. Ben Aissas, Noureddine Raouafis, Suzanne Joiret ${ }^{*}$, Alexa Courty $\ddagger^{*}$, and E. Maisonhaute ${ }^{*}$

† Sorbonne Universités, UPMC Univ Paris 06, UMR 8235, Laboratoire Interfaces et Systèmes Electrochimiques, F-75005 Paris, France.

CNRS, UMR 8235, LISE, F-75005, Paris, France

* Sorbonne Universités, UPMC Univ Paris 06, UMR 8233, Laboratoire MONARIS, F-75005 Paris, France.

CNRS, UMR 8233, Laboratoire MONARIS, F-75005, Paris, France

$\S$ Laboratoire de Chimie Analytique et Electrochimie, Département de Chimie, Faculté des Sciences de Tunis, Université de Tunis El Manar, Campus universitaire de Tunis El-Manar, 2092 Tunis El Manar, Tunisie.

e-mails of corresponding authors: alexa.courty@upmc.fr, suzanne.joiret@upmc.fr, emmanuel.maisonhaute@upmc.fr 


\begin{abstract}
There is a considerable interest for producing and understanding the optical and spectroscopic properties of ordered nanoparticles assemblies. Herein, we describe and interpret the optical absorbance and Raman properties of silver $5.9 \pm 0.3 \mathrm{~nm}$ diameter nanocrystals coated with dodecanethiol organized in highly ordered 3D superlattices of different heights. Each superlattice could be studied individually. A model based on Maxwell-Garnett formulation reproduces qualitatively the height and wavelength dependence of the absorbance. Importantly, because of their small size compared to traditional nanoparticles used in SERS, the large 3D distribution of hot spots generated by the silver superlattices allows to obtain easily SERS spectra of the surrounding ligands despite their intrinsic low Raman cross section. Accordingly, traces of thiophenol can be very easily detected.
\end{abstract}

keywords: Nanoparticles, Nanocrystals, Superlattices, Supracrystals, SERS, Plasmonic properties, Organization. 


\section{Introduction}

Optical properties of nanoobjects are still under considerable focus because of their many potential applications. For example, these nanoobjects allow making photonic crystals, optical waveguides or light havesting devices among others.[1,2] In this field there is an even stronger attention paid to plasmonic systems for which the electric field can induce collective oscillations in the metallic structures.[3-6] The main metals used for plasmonic applications are silver because of its well-defined and intense plasmon peak and gold due to its chemical stability and biocompatibility. When quantifying the behavior, a crucial parameter is the frequency dependence of the dielectric constant $\varepsilon$ of both the metal and the surrounding environment. Minute changes in $\varepsilon$ may be tracked, which allowed ultrasensitive biosensing for example using the Biacore system.[7, 8] While this commercial system remains on a longitudinal plasmon excitation in a continuous nanometer thick gold film, other systems are based on nanoparticles (NPs). In this approach, it is well established that size, size distribution and shape of the NPs are crucial for their optical absorption.[9] For example, rods display absorption at two specific wavelength (transverse and longitudinal) while spheres display a single maximum.[10,11] Several strategies are then under focus for optimizing the optical responses. The first one remains on electron lithography, which presents the great advantage of reproducibility.[12-16] Nevertheless, it is difficult to achieve resolutions of less than $10 \mathrm{~nm}$ and this method is quite expensive. Very reproducible systems on a large area are produced by nanosphere lithography followed by gold (electro)deposition but these present up to now rather low density of hot spots. $[17,18]$ In order to get smaller objects chemical synthesis of NPs is very popular and many different methods are reported.[19-29] 
In addition to plasmonic detection, silver and gold nanostructures offer the possibility for Surface Enhanced Raman Spectroscopy (SERS). Indeed, in the vicinity of a nanometric constriction, the electric field is modified and can be considerably amplified.[3] This property finds a great application to compensate the intrinsic low Raman cross section of molecular systems. Presently, the ultimate sensitivity of SERS is imposing this method as a mean to get fine molecular details about the surface structure and reactivity of molecular adsorbates.[18, 30] The amplification is even higher in the gap between two or more NPs, in the so-called "hot spot" so that a singlemolecule sensitivity has been reached.[5,31] Thus, dimers, trimers or more complicated structures have been elaborated.[32] In the same trend, in order to increase the density of hot spots, AlvarezPuebla et al. produced forests of nanorods.[33, 34] Another strategy proposed by Tian's group in Xiamen University is to trigger the SERS on an initially inactive surface by spreading SHell Isolated Nanoparticles Enhanced Raman Scattering made by encapsulating a SERS active gold nanoparticle by an insulating very thin layer of silica.[35] NPs SERS-based method suffer nevertheless from the random position of the hot spots on the surface. Moreover, the signal observed is usually not representative of the majority of the molecules, but only of the ones present in the hot spot environment. As a consequence, the global sensitivity remains also limited.

In this framework of intense activity about optical and spectroscopic properties of NPs, we report herein unique properties of highly ordered 3D superlattices made of silver nanocrystals (NCs) called supracrystals. For 3D assemblies, previous optical measurements were made on collections of supracrystal assemblies, which complicated the analysis particularly since the substrate contribution and individual properties depend on the supracrystal height $h_{\text {supra.[36] Apart from }}$ usual systems used in SERS, the silver NCs synthesized in this study have a low diameter (5.9 \pm $0.3 \mathrm{~nm})$. They are capped with dodecanethiol to prevent their coalescence and oxidation.[37, 38] 
This ligand can also be used as vibrational probe. Because of their very narrow size distribution, these silver NCs self-organize in fcc superlattices onto very large distances (several micrometers).[39-41] These superlattices, could thus be studied individually under an optical microscope. We describe below their formation and characterization, together with their optical and SERS properties.

\section{Synthesis and self-organization}

For obtaining long-range organizations, it is crucial to obtain size distribution below $10 \%$.[40, 42] For that, we relied onto a novel synthesis method published recently by some of us.[37, 43] We thus obtained large quantities of dodecanethiol coated silver NCs that can be subsequently redispersed in hexane or toluene. Each NCs synthesis was characterized by TEM, and a typical image is presented in figure 1. In this work size distribution histograms (cf. figure 1b) performed onto a collection of at least $500 \mathrm{NCs}$ displayed a standard deviation of less than $6 \%$. In agreement with literature, these NCs absorb light and present a Localized Surface Plasmon Resonance (LSPR) centered at $420 \mathrm{~nm}$ in colloidal suspensions.[37]
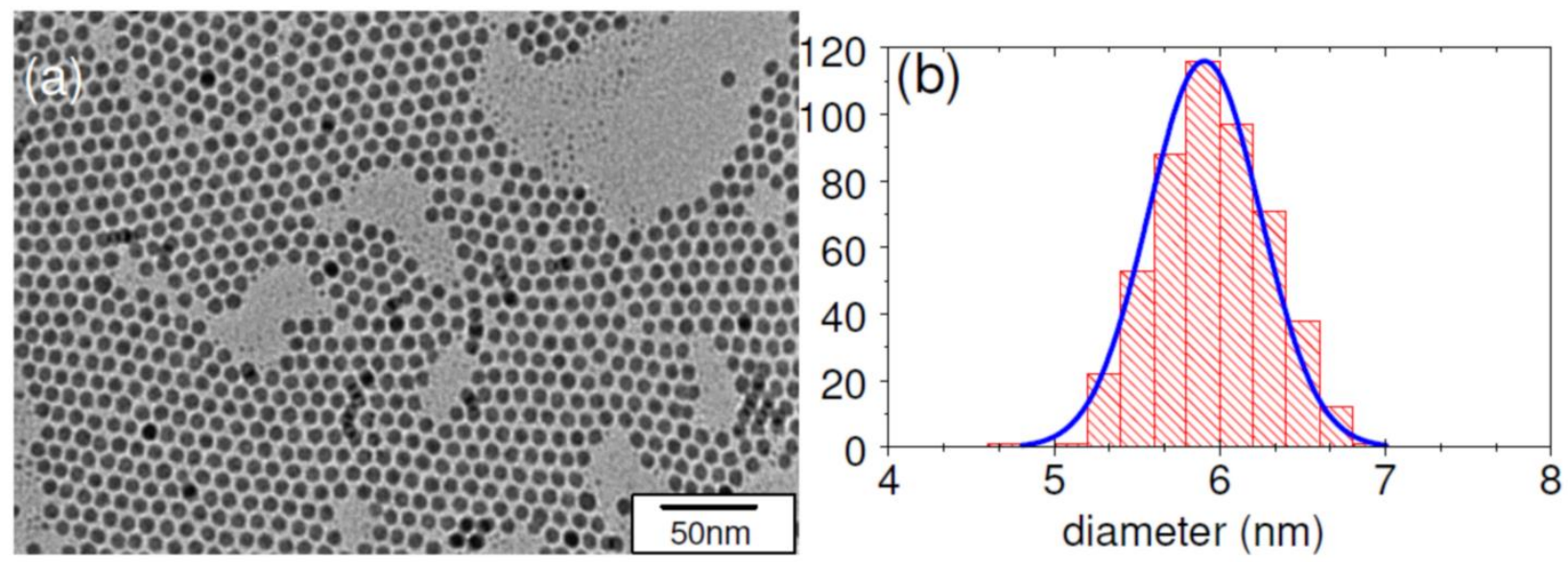
Figure 1. (a) TEM image of $5.9 \mathrm{~nm} \pm 0.3 \mathrm{~nm}$ diameter silver nanocrystals coated with dodecanethiol. (b) Corresponding size histogram. Standard deviation: 6\%.

Several methods were used to produce superlattices from a monolayer up to thick supracrystals. A graphical illustration of these methods is provided in figure S1. The substrates were made by evaporating a $10 \mathrm{~nm}$ of carbon by sputtering on glass microscope slides. In the first approach, a droplet of $2 \times 10^{-3}$ mol.L $\mathrm{L}^{-1}$ (in silver atoms) toluene solution was directly casted on the substrate.[42] Secondly, we deposited a $20 \mu \mathrm{L}$ hexane droplet (also $2 \times 10^{-3} \mathrm{molL}^{-1}$ ) on top of ethylene or diethyleneglycol.[44] These act as a bad solvent for the NCs that self-organize at the interface. After 30 mins, the film was transferred onto the glass slide. The third approach, was the so-called "immersion method".[40] The substrate was placed on the botton of a glass beaker. Then, $200 \mu \mathrm{L}$ of the AgNCs solution at $10^{-3} \mathrm{molL}^{-1}$ (in silver atoms) was added and the solution was left to evaporate under a nitrogen flux overnight. The substrate temperature was controlled and could vary between $25^{\circ} \mathrm{C}$ and $60^{\circ} \mathrm{C}$.

Each sample was imaged by SEM-FEG to check the local organization and by Atomic Force Microscopy (AFM) to determine $h_{\text {supra. }}$ For multilayers, Small Angle X-Ray Diffraction (SAXRD) was also performed in order to confirm the fcc arrangement of the NCs assemblies in agreement with previous studies (see figure S2).[41] The edge-edge distance between the silver cores of two NCs was thus determined from $\mathrm{d}_{(111)}$ spacing as $1.9 \pm 0.2 \mathrm{~nm}$, slightly larger than the dodecanethiol molecular length.[45] Of major importance, it was independent of the sample preparation. The SEM-FEG image displayed in figure $2 \mathrm{a}$ is a representative example of a $1 \mu \mathrm{m}$ large supracrystal attesting a nearly perfect organization. In all cases, we could easily identify superlattices with 
lateral dimensions larger than $1 \mu \mathrm{m}$. Additional images of superlattices obtained with different deposition methods are displayed in figure S3. For optical measurements (see below), we chose superlattices ranging over at least $3 \mu \mathrm{m}$, therefore larger than the surface analyzed in optical and microRaman measurements. In addition, we measured $h_{\text {supra }}$ for many supracrystals and for each deposition methods by AFM. Onto each supracrystal, a height histogram confirmed that $h_{\text {supra }}$ was very homogeneous since variations around only one monolayer were observed. Various organizations and height distributions are represented in figures 2c and S4. Depending on the deposition method, different ranges of $h_{\text {supra }}$, from 9 to $350 \mathrm{~nm}$ could be obtained. They can be converted in a number of NCs layers relying on equation (1):[46]

$$
h_{\text {supra }}=\left(D_{N C}\right)+\left(N_{\text {layer }}-1\right)\left(D_{N C}+d_{N C-N C}\right) \sqrt{\frac{2}{3}}
$$

Where $D_{\mathrm{NC}}$ is the NC diameter (metallic core, here $5.9 \mathrm{~nm}$ ), $N_{\text {layer }}$ is the number of layers and $d_{\mathrm{NC}-\mathrm{NC}}(1.9 \mathrm{~nm})$ is the minimal edge-edge distance between two NCs deduced from SAXRD measurements. We hence deduced that we could span a large range of $h_{\text {supra }}$ from 1 up to 54 layers. ${ }^{1}$

\footnotetext{
${ }^{1}$ It is noticeable that the height of one NCs monolayer deposited on a solid substrate has been already estimated by AFM measurements combined with SEM and corresponded to the average diameter of the NCs metallic core (reference 42). The slightly superior value obtained here for a monolayer is still acceptable. It may be due either to different packing of the ligands on the substrate and/or different imaging conditions and larger surface roughness of our glass substrates.
} 

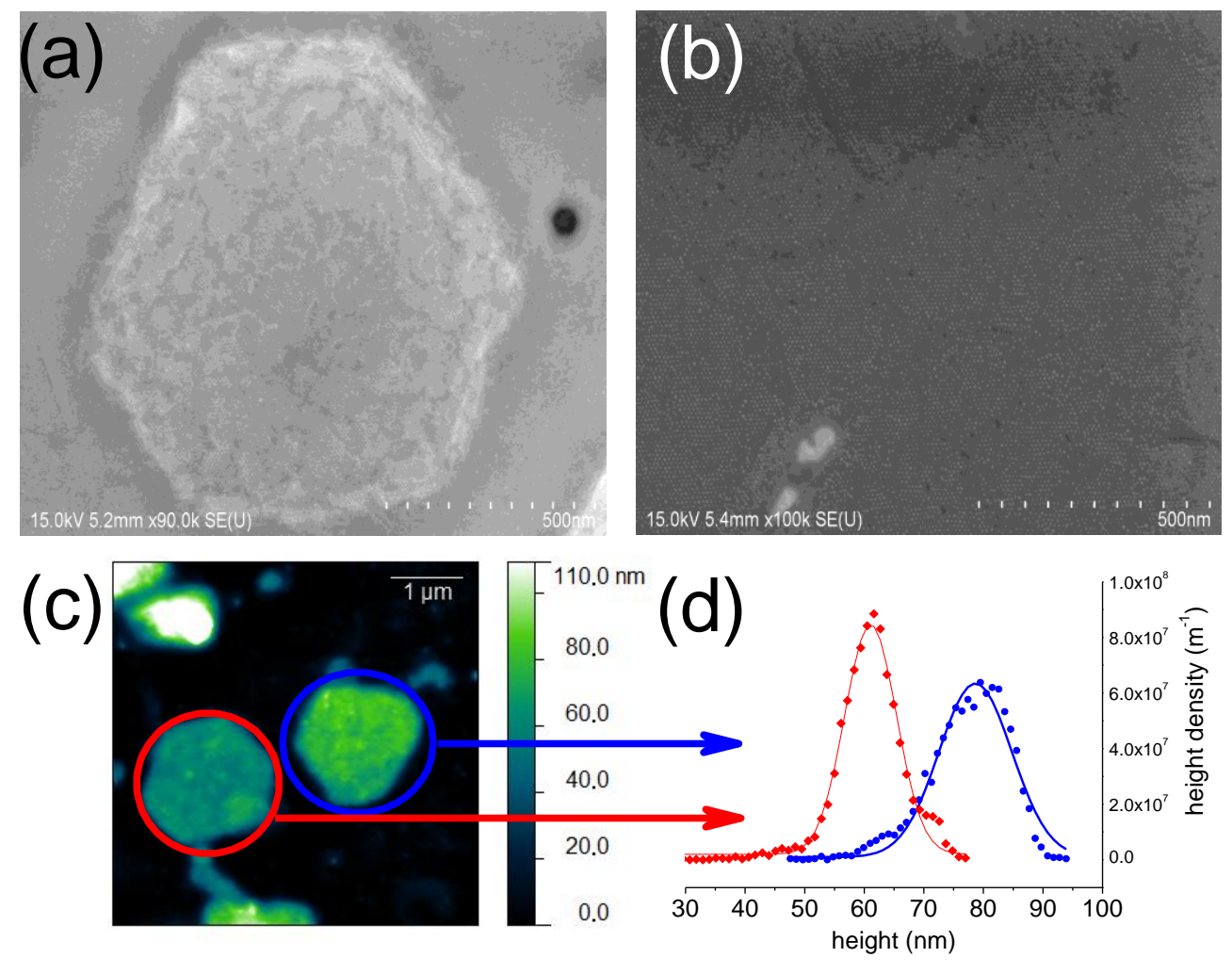

Figure 2. (a), (b) SEM-FEG images evidencing a long range organization for two different individuals supracrystals obtained by drop casting a solution of silver NCs. (c) AFM image and (d) Corresponding height distributions for two other supracrystals. 


\section{Optical properties}

Following these careful sample preparations, we established a set-up for measuring both the optical and Raman properties of individual supracrystals in the visible range at the same position. Our strategy is similar to the one reported by Murray to study optical properties of binary thin superlattices.[44] To the best of our knowledge, such an approach has never been reported so far onto individual thick superlattices. Indeed, at present, only macroscopic optical properties for many superlattices present in a millimetric spot were measured by Taleb et al.[36] Nevertheless, since physical and more specifically optical properties of NCs ensembles differ from the one of an isolated system,[47-49] it is then extremely important to discriminate between differences (shift and broadening, see below) arising from a perfect organization inside a single supracrystal or from inhomogeneities necessarily present if the beam light encompasses many supracrystals. This step is necessary for further use of plasmonic properties of supracrystals in applied devices.

To do so, we took advantage of the confocal microscope of our Raman spectrometer as depicted in supporting information. For reflectance measurements, we used an optical fiber to introduce white light on the side of the microscope and borrowed the optical path usually used for Raman. We used a 100x objective with a confocal hole of $300 \mu \mathrm{m}$, thus analyzing an area of $3 \mu \mathrm{m}$ diameter. In this set up, the sensitivity of our CCD allowed spanning a wavelength range from 450 to 800 $\mathrm{nm}$. This way, the wavelength dependence of the light emitted and CCD sensitivity are directly taken into account. During these acquisitions, the notch filter of the Raman spectrometer was not

removed to keep all settings identical during optical and Raman measurements (see below). A 
reference spectrum was acquired onto aluminum since this metal displays an almost constant reflectivity (0.9) in the visible range.[50] The reflectance spectrum $R$ was thus determined as:

$$
R(\lambda)=I(\lambda) /\left(0.9 I_{\mathrm{ref}}(\lambda)\right)
$$

Figure 3a presents typical reflectance spectra obtained by this method for three different superlattices with different $h_{\text {supra. }}$.

In order to measure the transmittance $\mathrm{T}$, a similar procedure was performed excepted that the substrate was enlighten from below so that $\mathrm{T}$ is given by:

$$
T(\lambda)=I(\lambda) / I_{\text {ref }}(\lambda)
$$

where here $I_{\text {ref }}$ is obtained by monitoring the light transmitted at a place where no NCs were deposited. Interestingly, figure $3 \mathrm{~b}$ revealed that for $\lambda>550 \mathrm{~nm}$, transmittance raised importantly up to values that could be higher than 0.6 , which may be interesting to conceive in the future new transparent electrodes.[51, 52]

Accordingly, the local absorbance spectra (see figure 3c) were calculated as:

$$
A(\lambda)=1-R(\lambda)-T(\lambda)
$$



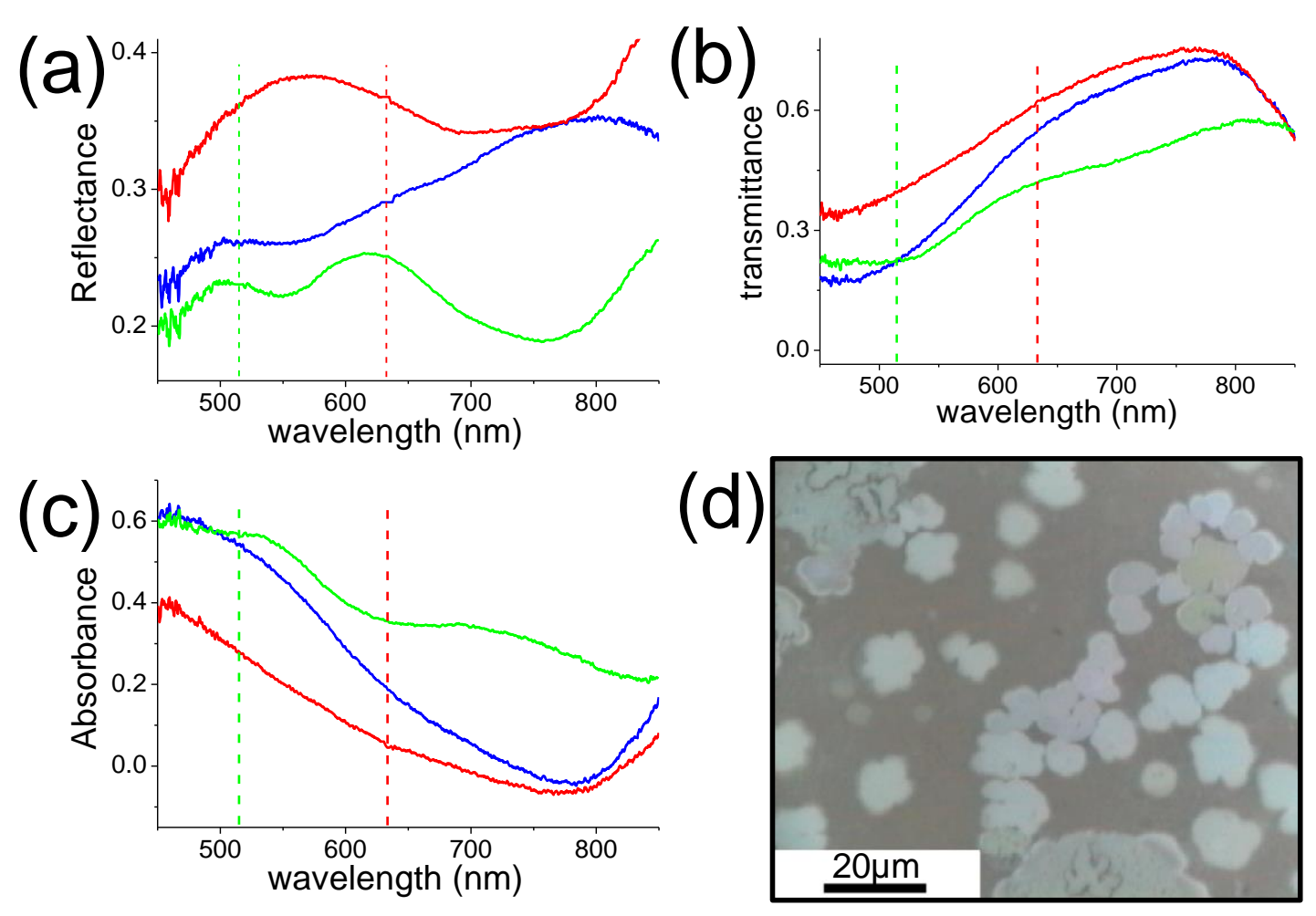

Figure 3. Reflectance (a), transmittance (b) and absorbance (c) spectra for three individuals supracrystals with different heights $(\mathrm{red}=49 \mathrm{~nm}$, blue $=122 \mathrm{~nm}$, green $=204 \mathrm{~nm})$. (d) optical image of a typical sample.

We applied this methodology for a large range of $h_{\text {supra }}$ determined by AFM, and observed a clear evolution of the spectra. All absorbance curves were compiled in a 3D representation displayed in Figure 4. First, it was noticeable that at short wavelength the absorbance became almost constant for large $h_{\text {supra. }}$ Second, due to the interparticle plasmon coupling, $A(\lambda)$ raised and the LSPR band broadened when the number of layers increased.[3,53] 


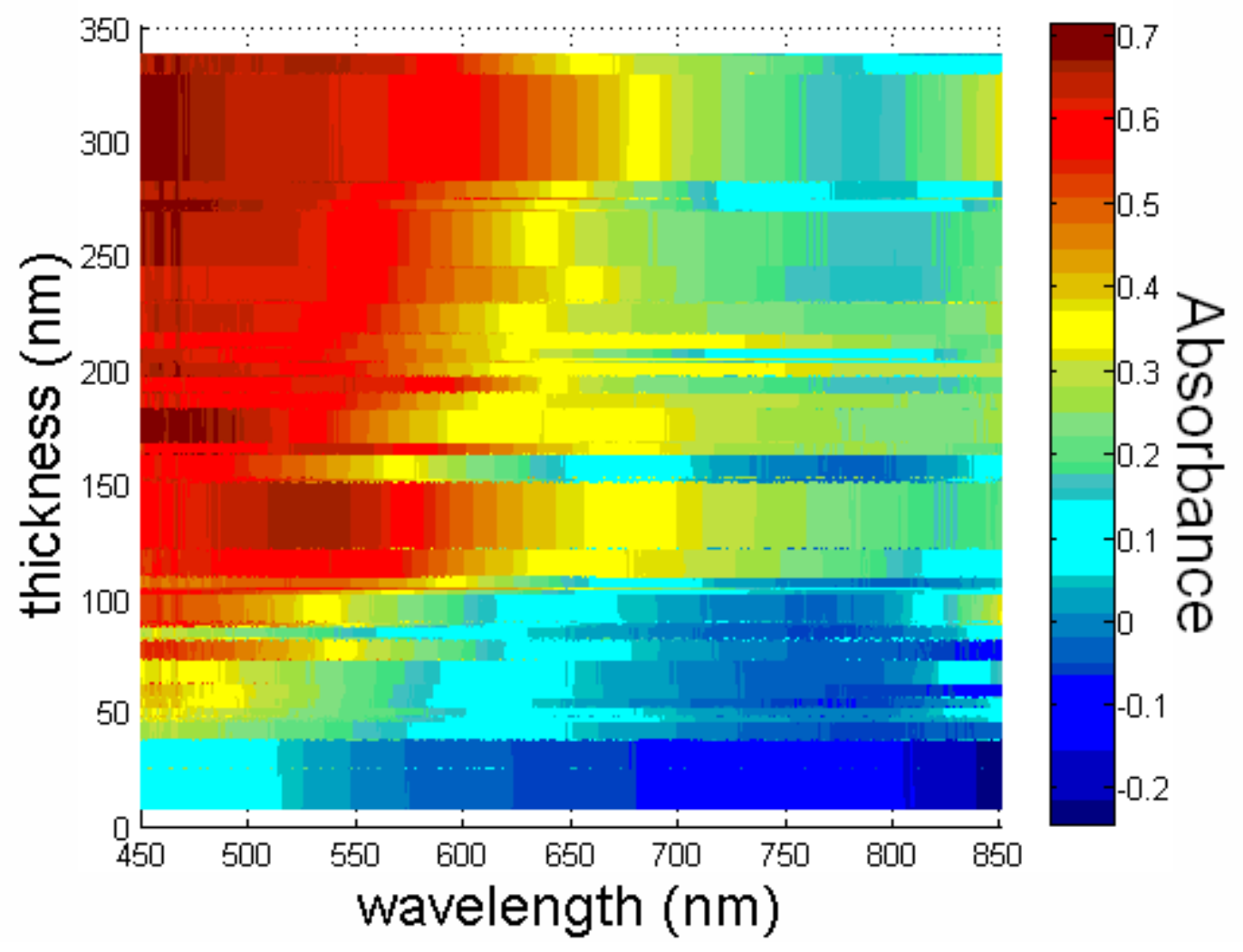

Figure 4. Experimental absorbance of individual supracrystals of different heights, for wavelength between $450 \mathrm{~nm}$ and $850 \mathrm{~nm}$.

The great homogeneity of our systems stimulated a more indepth interpretation of the spectra in order to identify the physical parameters that influence the spectral properties of our assemblies. All layers including the glass modified with carbon substrate and also the air needed to be considered in addition to the supracrystal film. To this respect, Tomlin determined analytically $R$, $T$ and $A$ for multilayer films having different dielectric properties.[54] The corresponding formulas are reported in ESM. 
Following Tomlin, the optical indexes of both the substrate $\left(n_{2}-\mathrm{i} k_{2}\right)$ and the supracrystal $\left(n_{1}-\mathrm{i} k_{1}\right)$ are required. They are related to their dielectric constants by:

$$
n_{1,2}-i k_{1,2}=\sqrt{\varepsilon_{1,2}^{\prime}-\varepsilon^{\prime \prime}{ }_{1,2}}
$$

where $\varepsilon_{1,2}^{\prime}$ and $\varepsilon_{1,2}^{\prime \prime}$ are respectively the real and imaginary components of the dielectric constants for both media.

For the supracrystal, $n_{1}-\mathrm{i} k_{1}$ is however unknown and should be estimated. For that, we relied on the Maxwell-Garnett theory. This translated into:

$$
n_{1}-i k_{1}=\sqrt{\varepsilon_{m} \frac{\varepsilon_{N C}(1+2 q)+2 \varepsilon_{m}(1-q)}{\varepsilon_{N C}(1-q)+\varepsilon_{m}(2+q)}}
$$

Where $\varepsilon_{\mathrm{m}}$ and $\varepsilon_{\mathrm{NC}}$ are the dielectric constants of the surrounding medium and $\mathrm{NC}$ respectively. $q$ was the volumic fraction occupied by the NCs. This model is available for $q<0.5$ which is the case here. Indeed, for $5.9 \mathrm{~nm}$ diameter NCs coated with dodecanethiol in a perfectly ordered fcc supracrystal, we obtained $q=0.31$. ENC was then evaluated following a corrected Drude model according to:

$$
\varepsilon_{N C}=\varepsilon_{b}-\frac{\omega_{p}^{2}}{\omega\left(\omega+\frac{i}{\tau}\right)}
$$

$\varepsilon_{\mathrm{b}}=4.32 \mathrm{eV}$ was the polarisability induced by $\mathrm{d}$ electrons and $\omega_{\mathrm{p}}=8.76 \mathrm{eV}$ was the plasmon frequency. These values were evaluated from a fit of the experimental data for bulk silver.[55] $\tau$ was the mean electron collision time which changes with the size of the $\mathrm{NC}$ according to:

$$
\frac{1}{\tau}=\frac{1}{\tau_{0}}+\frac{v_{f}}{R_{N C} / \Gamma}
$$


Here, $\tau_{0}$ and $v_{\mathrm{f}}$ refer to collision time and Fermi velocity for bulk silver, $R_{\mathrm{NC}}$ is the NC radius and $\Gamma$ a correction factor accounting for sulfur adsorption at the surface of the NCs.[24, 56]

In figure 5 the simulated absorbance reproduces qualitatively well the experimental observations, underlining that even this simple formulation tracked the physics of the system. Here, the parameters ascribed were $q=0.31, \Gamma=1.5$ and $\varepsilon_{\mathrm{m}}=2.16$ for dodecanethiol. In supporting information (see figure S7), we also present three fits of the experimental spectra but for which $\Gamma$ and $\varepsilon_{\mathrm{m}}$ were allowed to vary. For thick films (high $h_{\text {supra }}$ ), we observed that equations (5-8) reproduced correctly the experimental optical spectra using $\varepsilon_{\mathrm{m}}$ values about $2.4 \pm 0.3$, thus very close to the one of dodecanethiol. For low $h_{\text {supra, }}$ we could also reproduce the experimental data, but using a larger range of $\varepsilon_{\mathrm{m}}$ values. This apparent deviation of $\varepsilon_{\mathrm{m}}$ may stem from the necessity to correct Maxwell-Garnett formulation for thin films.[57] Also, in this model, NCs interactions were in fact taken into account only through the volumic fraction $q$ (equation 6). Further theoretical investigations incorporating specific chemical effects and NCs plasmon crystals coupling in a fcc lattice will be performed in the future in order to explain this variation of apparent effective dielectric constant.[3, 24, 56]

Noticeably, an oscillatory behavior not observed in the experiments because of experimental uncertainties appeared in the simulation. We checked that it was in fact solely due to multiple reflections that produced interferences in the film. Last, but not least, the model explained the larger bandwidth observed for higher $h_{\text {supra }}$ which was therefore not ascribed to defects inducing a broader distribution of interparticle distances within the superlattice. 


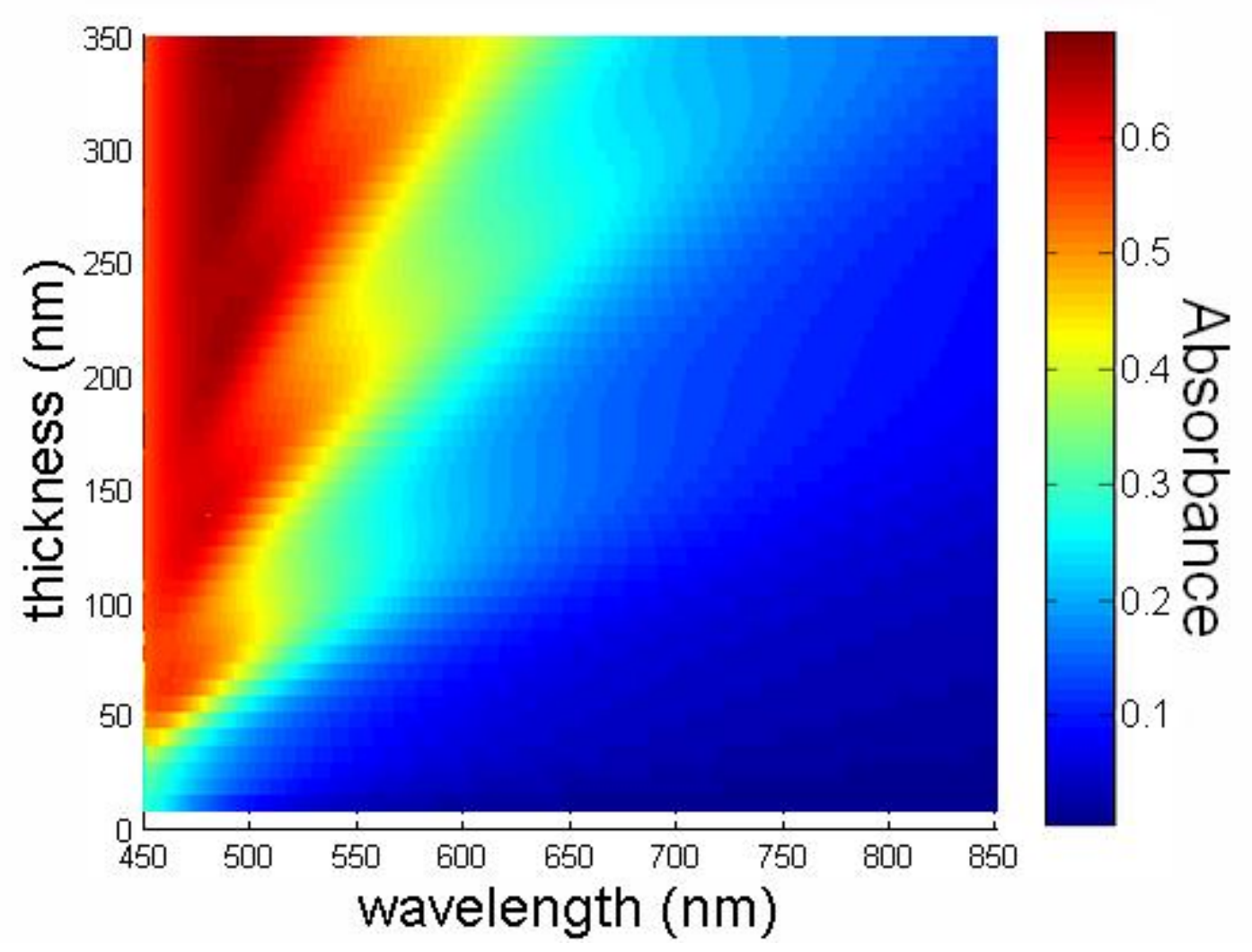

Figure 5. Simulated absorbance for different supracrystals heights $h_{\text {supra }}$, for wavelength between $450 \mathrm{~nm}$ and $850 \mathrm{~nm}$ with the following parameters: $q=0.312, \varepsilon_{\mathrm{m}}=2.16, \Gamma=1.5$. See text for details.

In summary, the superlattices presented here display unique properties and open an avenue for a novel class of tunable plasmonic devices. Additional observations furthermore evidenced that their optical properties are identical on the whole surface of each superlattice, which is consistent with a uniform $h_{\text {supra }}$ measured by AFM. Furthermore, for facetted supracrystals, we did not detect any dependence with the polarization orientation towards the facet. Our objects are thus much different from observations with facetted bulk silver and gold large nanoparticles that displayed a 
dependence with polarization and position of the excitation onto the object. $[9,58,59]$ Their easy understandable behavior together with their reproducibility represent a great advantage for their integration in optically active devices.

\section{SERS properties of silver NCs superlattices}

In direct connection with optical measurements we analysed the SERS spectra obtained with laser excitation wavelengths of 514 and $633 \mathrm{~nm}$ on exactly the same individual supracrystals. These wavelengths are included in the LSPR band of the silver NCs superlattices (see figure 3). Several spectra corresponding to different $h_{\text {supra }}$ are displayed in figure 6. Here, the vibrational signature of the dodecanethiolate ligands adsorbed on the NCs surface were clearly observed (see figure 6 and table S1).[60, 61] It is noticeable that though the cross section of this molecule is well known to be rather weak, Raman spectra could be obtained with relatively low power excitations and integration times (respectively 20 to $70 \mu \mathrm{W}$ depending on the laser and $300 \mathrm{~s}$ ).
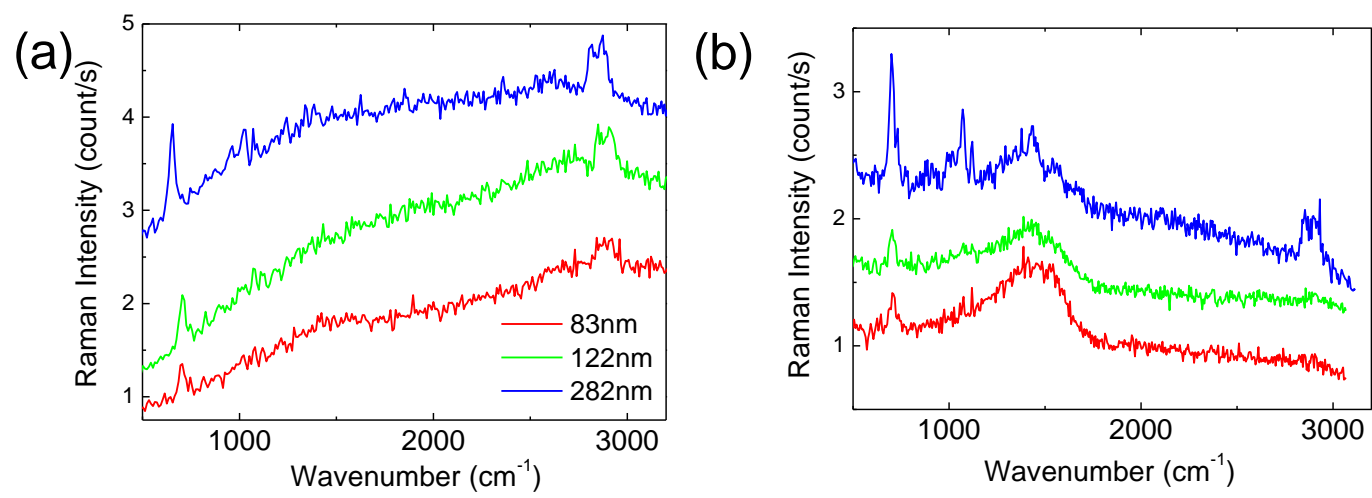

Figure 6. SERS spectra of the dodecanethiolate molecules coating the silver nanocrystals performed on three individual supracrystals having different heights $h_{\text {supra }}$ (red: $83 \mathrm{~nm}$, blue: 282 $\mathrm{nm}$, green: $122 \mathrm{~nm}$ ) for two laser excitation wavelengths. (a) $514 \mathrm{~nm}$, laser power $20 \mu \mathrm{W}$ and (b) 
$633 \mathrm{~nm}$, laser power, $70 \mu \mathrm{W}$. Acquisition time: $300 \mathrm{~s}$. The spectra have been shifted for the sake of clarity.

A reference spectrum obtained for a sodium thiolate powder is displayed in figure S8. Band assignment is given in table S1. On the silver superlattices, the trans C-S stretching mode at $v_{t}=$ $700 \mathrm{~cm}^{-1}$ is observed. The reference displayed this mode at $v_{\mathrm{t}}=741 \mathrm{~cm}^{-1}$. This shift upon adsorption was in agreement with literature.[60] Also, as reported earlier,[61] $v(\mathrm{~S}-\mathrm{H})$ was missing since thiols lost their protons upon adsorption via the sulfur atom onto the metal surface. Moreover, the C-S mode was much more amplified than the $\mathrm{C}-\mathrm{H}$ vibrational modes $\left(v_{\mathrm{sym}}, v_{\text {asym }}\right.$ and Fermi resonance) present between 2850 and $2950 \mathrm{~cm}^{-1}$.[60] This can be rationalized considering that the C-S bond is closer to the metallic cores and then positioned in an environment where the electric field is maximum.[62] Since this band was very well-defined and corresponded to a single mode, we refined the analysis and recorded its intensity for all superlattices and for both laser excitation wavelenths. In figure 6 , we noted that $v_{\mathrm{t}}(\mathrm{C}-\mathrm{S})$ increased with $h_{\text {supra, }}$ but reached saturation in the range $100-150 \mathrm{~nm}$ at $514 \mathrm{~nm}$ whereas a continuous increase was observed at $633 \mathrm{~nm}$. This was in agreement with optical measurements for which absorbance was higher at short wavelengths (see figure 3). Moreover, in the spectra, the broad signal near $1500 \mathrm{~cm}^{-1}$ corresponding to amorphous carbon lying beneath the supracrystal decreased and then disappeared at $514 \mathrm{~nm}$ whereas it was always present at $633 \mathrm{~nm}$.

In order to be more quantitative, we extracted from figures 4 and 5 the absorbances at 514 and $633 \mathrm{~nm}$. They are reported in figure 7. 


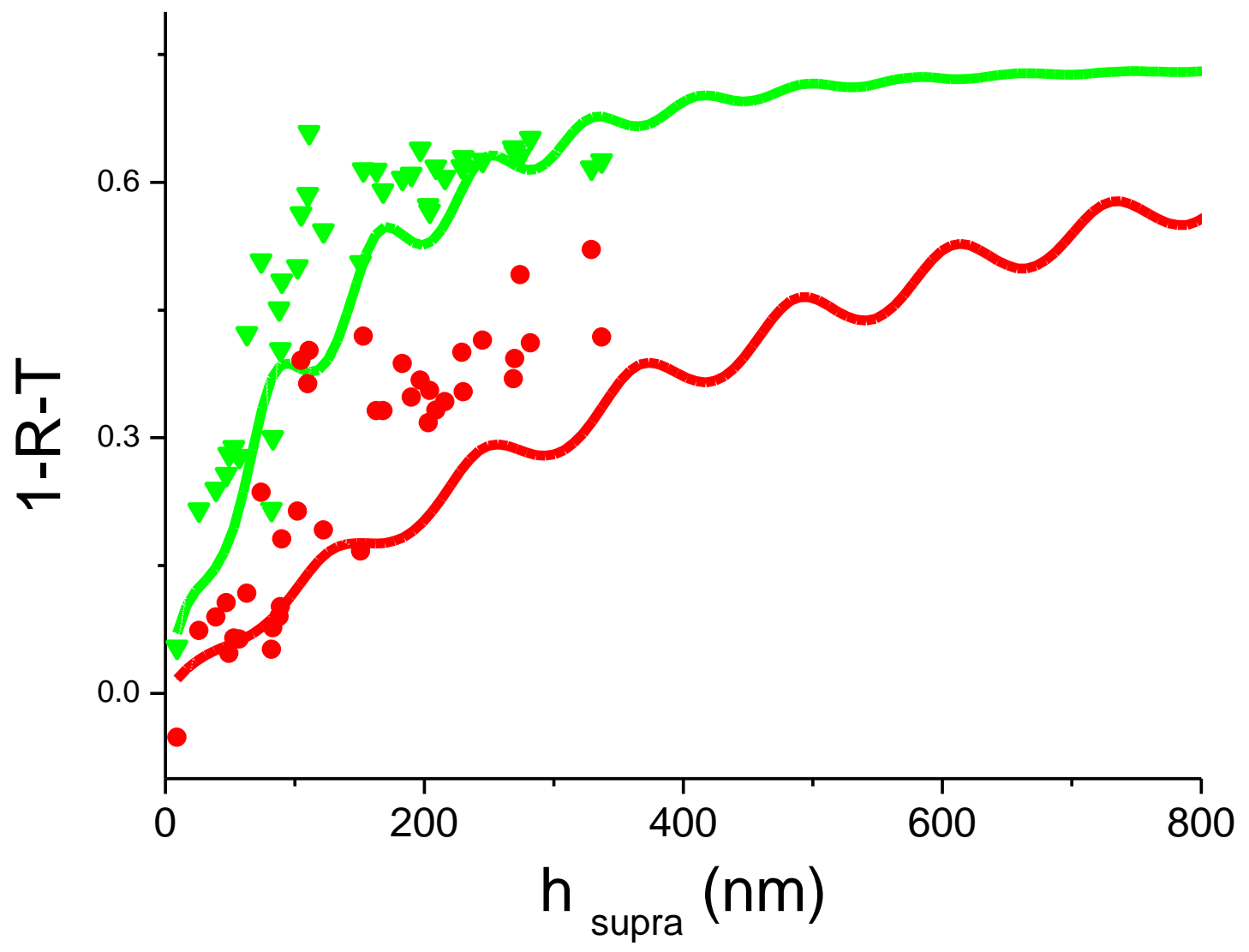

Figure 7. Experimental $(\nabla: 514 \mathrm{~nm} / \bullet 633 \mathrm{~nm})$ and simulated (lines) absorbances at $514 \mathrm{~nm}$ (green) and $633 \mathrm{~nm}$ (red) for silver supracrystals of different heights $h_{\text {supra. }}$

Accordingly, at $514 \mathrm{~nm}$ a plateau is reached near $115 \mathrm{~nm}$ whereas at $633 \mathrm{~nm}$ absorbance is still increasing even for the thicker supracrystals (around $350 \mathrm{~nm}$ ) considered in this study.

Therefore, both Raman and optical measurements agreed that the green laser probed distances equal or smaller than $115 \mathrm{~nm}$, whereas the red one probed the whole sample. By comparison with 
the spectrum of dodecanethiolate powder, enhancement factors could then be determined.[63] With the $514 \mathrm{~nm}$ laser, we considered a maximum analyzed depth of $115 \mathrm{~nm}$ corresponding to 17 layers. Here, each NC was estimated to be capped by around 690 thiols.[37] With a laser spot surface of $1 \mu \mathrm{m}^{2}$, we estimated that $1.10^{7}$ dodecanethiolate molecules were probed for each layer. Figure 8 reports the calculated enhancements factors for both wavelengths and for exactly the same supracystals and the same position inside each supracrystal for which optical measurements were performed.

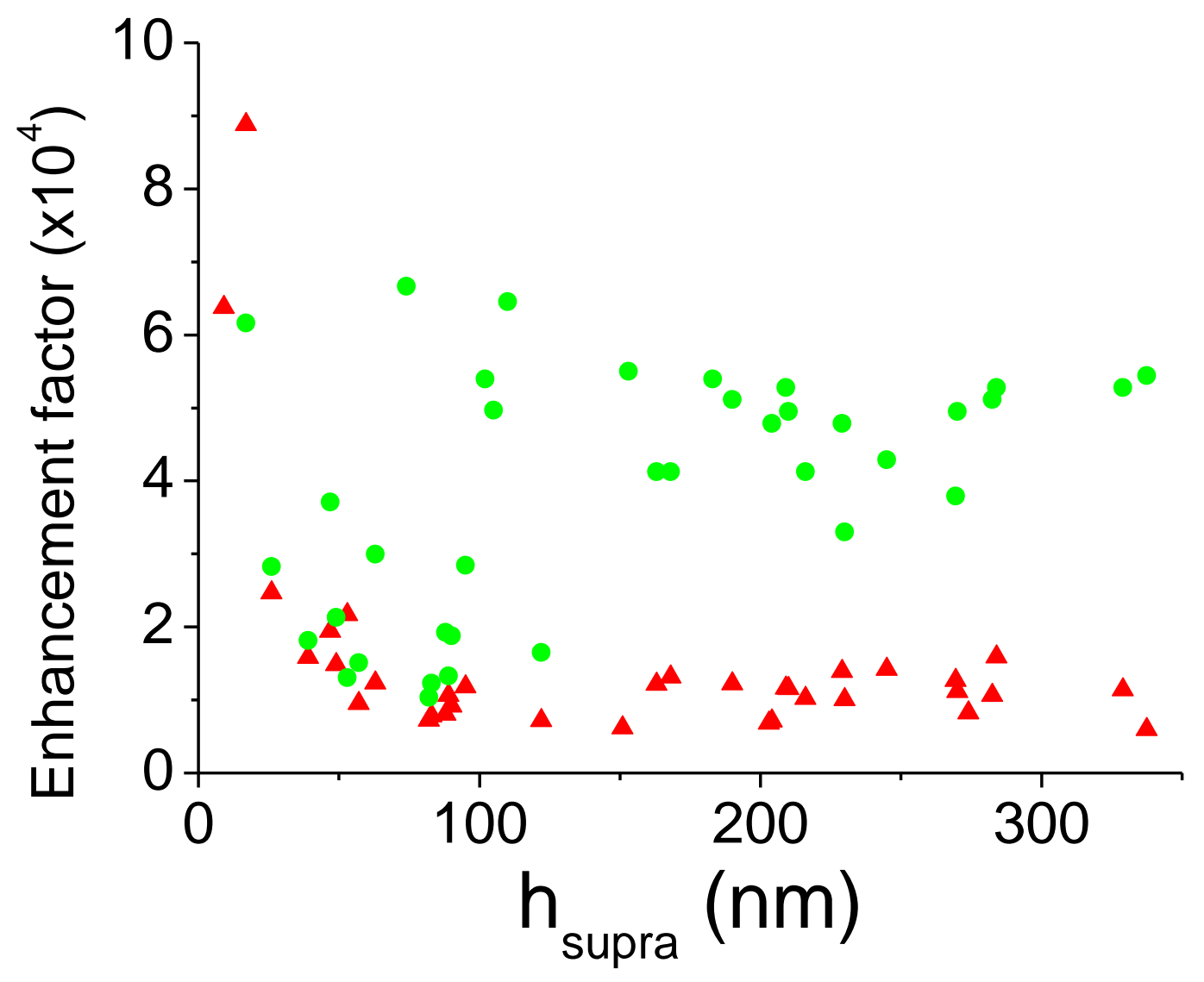

Figure 8. Experimental enhancement factors determined at $514 \mathrm{~nm}(\bullet)$ and $633 \mathrm{~nm}(\Delta)$ for all superlattices studied here. 
Detection was easier with thicker superlattices since more molecules were probed but could be achieved without difficulty down to one monolayer. We observed that enhancement factors did

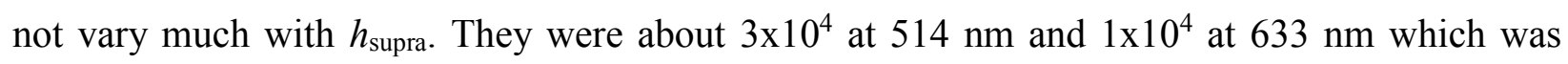
consistent with a smaller absorbance at $633 \mathrm{~nm}$. Nevertheless, it was indeed particularly noticeable to obtain such large values for this aliphatic system and NCs much smaller than the ones usually used in SERS. This extreme sensitivity resulted from the large number of hot spots filled by dodecanethiolates in the silver superlattices. At the surface of a fcc supracrystal, we calculated a hot spot density of $5.8 \times 10^{16} \mathrm{~m}^{-2}$, which corresponded to $5.8 \times 10^{4}$ hot spots for a laser beam of 1 $\mu \mathrm{m}^{2}$.

To better emphasize the very good detection capability at the surface of the superlattices, we replaced some of the alkyl ligands with thiophenol, a reference molecule in SERS studies.[16, 18, 64] For that, we left a sample covered with thick supracrystals in a $10 \mu \mathrm{M}$ thiophenol solution in acetonitrile for 90 mins. As acetonitrile is a poor solvent for the NCs, it cannot dissolve the silver supracrystals. The sample was then left for 150 mins in neat acetonitrile in order to remove free and physisorbed thiophenol. The corresponding SERS spectra (spectra (i) and (ii) obtained for both laser excitation wavelengths 514 and $633 \mathrm{~nm}$ ) are represented in figure 9. They revealed the presence of dodecanethiolate and thiophenol in agreement with the SERS spectra of the pure compounds (Figure S8 and Figure 9 spectrum (iii)). In literature, the maximum coverage for thiophenol on $\mathrm{Ag}(111)$ has been estimated to $0.544 \mathrm{nmol}^{\mathrm{cm}}{ }^{-2}$.[65] Obviously in our experiment the coverage was much smaller but could however not be estimated. Hence only a minimum enhancement factor can be deduced. We considered the $1571 \mathrm{~cm}^{-1}$ band corresponding to the C-C symmetric stretching vibrational mode which is well-defined and does not appear in the 
dodecanthiolate spectrum (see table S1). We then deduced a minimal enhancement of $4 \times 10^{6}$. It was however probably much higher and will be more precisely evaluated in a further study.

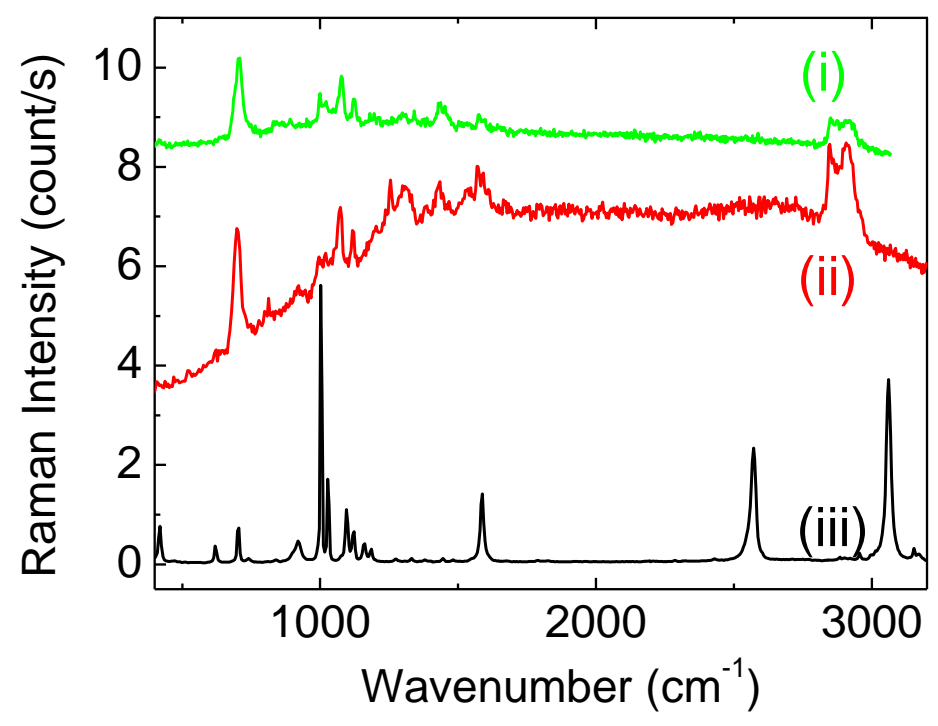

Figure 9. SERS spectra of individual supracrystal modified with thiophenol for two laser excitation wavelengths. (i) $514 \mathrm{~nm}$, laser power $20 \mu \mathrm{W}$ and (ii) $633 \mathrm{~nm}$, laser power, $70 \mu \mathrm{W}$. Acquisition time: 300 s. (iii) Raman spectrum of pure thiophenol ( $514 \mathrm{~nm}, 4 \mathrm{~mW}, 1 \mathrm{~s})$. The spectra have been shifted for the sake of clarity.

The very facile detection of thiophenol paved the way for further ultrasensitive SERS detection and showed that highly ordered 3D NCs superlattices can be used as SERS platform with high reproducibility and sensitivity. 


\section{Conclusions}

We have developed in this work new substrates that are of great interest for future optical and SERS applications. They are based on large scale and well-ordered $5.9 \mathrm{~nm}$ silver nanocrystals superlattices. First, the substrate preparation allowed to tune the supracrystal height from 9 to 350 $\mathrm{nm}$, thus from 1 to 54 layers. Second, we elaborated a set-up for measuring easily optical properties of individual supracrystals. This method does not require sophisticated SNOM techniques since the supracrystals were smooth enough. It was observed that the absorbance spectra of the silver supracrystals could be well reproduced with a Maxwell-Garnett approach. As these are conductive and relatively transparent in the red region, they could represent a new generation of electrodes adapted for mechanistic studies.[51, 52, 66-69] The developed methodology may be applied to other metamaterials including other metals or alloys, binary assemblies of NCs or organic matrix. The measurements would benefit from further theoretical investigations to calculate the local enhancement of the electric field at different positions inside or above the superlattices.

Finally, these fabricated superlattices with dimensions of several micrometers exhibited for the first time high and reproducible SERS activity of their capping ligands or small amount of thiophenol. These substrates are very different from other SERS-active systems which usually resort from NPs of much larger sizes.[70] As the ligands may be easily exchanged by functional molecules, these substrate may open unprecedented analytical possibilities for ultrasensitive SERS. Because of the small NCs size, the supracrystal surfaces are smooth and provide a higher density of hot spots leading to a potential better detection. In further work, we will describe SERS measurements onto functional molecules and also take advantage of the conduction properties of these appealing metamaterials. 


\section{Acknowledgements}

This work was supported by the Labex MiChem part of the French state funds managed by the ANR within the Investissements d'Avenir program under reference ANR-11-IDEX-0004-02. We greatfully thank Ms Françoise Pillier, Mr. David Montero and Dr. Anh-Tu Ngo for SEM-FEG imaging, Dr. Pierre-Antoine Albouy (LPS, Université Paris-Sud) for SAXRD measurements, Ms. Florence Billon for carbon sputtering onto the glass slides, and Ms. Marie Steffenhaguen for her help in data handling. We also thank Pr. Bruno Palpant for helpful discussions.

Electronic Supplementary Material. Nanocrystals synthesis and fabrication of superlattices by different deposition methods, SAXRD pattern, additional SEM-FEG and AFM images of superlattices, details of optical and Raman measurements, optical model, fit of experimental spectra, reference spectrum of dodecanethiolate. 


\section{References}

[1] Novotny, L.; Hecht, B. Principles of Nano-Optics; Cambridge University Press, 2012.

[2] Zhao, L. L.; Kelly, K. L.; Schatz, G. C. The extinction spectra of silver nanoparticle arrays: Influence of array structure on plasmon resonance wavelength and width. J. Phys. Chem. B 2003, 107, 7343-7350.

[3] Halas, N. J.; Lal, S.; Chang, W. S.; Link, S.; Nordlander, P. Plasmons in Strongly Coupled Metallic Nanostructures. Chem. Rev. 2011, 111, 3913-3961.

[4] Jain, P. K.; El-Sayed, M. A. Plasmonic coupling in noble metal nanostructures. Chem. Phys. Lett. 2010, 487, 153-164.

[5] Sharma, B.; Cardinal, M. F.; Kleinman, S. L.; Greeneltch, N. G.; Frontiera, R. R.; Blaber, M. G.; Schatz, G. C.; Van Duyne, R. P. High-performance SERS substrates: Advances and challenges. MRS Bull. 2013, 38, 615-624.

[6] Batchelor-McAuley, C.; Martinez-Marrades, A.; Tschulik, K.; Patel, A. N.; Combellas, C.; Kanoufi, F.; Tessier, G.; Compton, R. G. Simultaneous electrochemical and 3D optical imaging of silver nanoparticle oxidation. Chem. Phys. Lett. 2014, 597, $20-25$.

[7] Nagata, K.; Handa, H. Real-Time Analysis of Biomolecular Interactions: Applications of Biacore; Springer, Japan, 2000.

[8] Navratilova, I.; Besnard, J.; Hopkins, A. L. Screening for GPCR Ligands Using Surface Plasmon Resonance. ACS Med. Chem. Lett. 2011, 2, 549-554.

[9] Le Moal, E.; Marguet, S.; Rogez, B.; Mukherjee, S.; Dos Santos, P.; Boer-Duchemin, E.; Comtet, G.; Dujardin, G. An electrically excited nanoscale light source with active angular control of the emitted light. Nano Lett. 2013, 13, 4198-4205.

[10] Kelly, K. L.; Coronado, E.; Zhao, L. L.; Schatz, G. C. The optical properties of metal nanoparticles: The influence of size, shape, and dielectric environment. J. Phys. Chem. B 2003, 107, 668-677.

[11] Jain, P. K.; Lee, K. S.; El-Sayed, I. H.; El-Sayed, M. A. Calculated absorption and scattering properties of gold nanoparticles of different size, shape, and composition: Applications in biological imaging and biomedicine. J. Phys. Chem. B 2006, 110, 72387248.

[12] Jain, P. K.; Huang, W. Y.; El-Sayed, M. A. On the universal scaling behavior of the distance decay of plasmon coupling in metal nanoparticle pairs: A plasmon ruler equation. Nano Lett. 2007, 7, 2080-2088.

[13] Grand, J.; de la Chapelle, M. L.; Bijeon, J. L.; Adam, P. M.; Vial, A.; Royer, P. Role of localized surface plasmons in surface-enhanced Raman scattering of shape-controlled metallic particles in regular arrays. Phys. Rev. B 2005, 72.

[14] Kessentini, S.; Barchiesi, D.; D'Andrea, C.; Toma, A.; Guillot, N.; Di Fabrizio, E.; Fazio, B.; Marago, O. M.; Gucciardi, P. G.; de la Chapelle, M. L. Gold Dimer Nanoantenna with Slanted Gap for Tunable LSPR and Improved SERS. J. Phys. Chem. C 2014, 118, 32093219.

[15] Wang, X. L.; Gogol, P.; Cambril, E.; Palpant, B. Near- and Far-Field Effects on the Plasmon Coupling in Gold Nanoparticle Arrays. J. Phys. Chem. C 2012, 116, 2474124747. 
[16] Wang, Y.; Lu, N.; Wang, W.; Liu, L.; Feng, L.; Zeng, Z.; Li, H.; Xu, W.; Wu, Z.; Hu, W.; Lu, Y.; Chi, L. Highly effective and reproducible surface-enhanced Raman scattering substrates based on Ag pyramidal arrays. Nano Res. 2013, 6, 159-166.

[17] Johnson, R. P.; Richardson, J. A.; Brown, T.; Bartlett, P. N. A Label-Free, Electrochemical SERS-Based Assay for Detection of DNA Hybridization and Discrimination of Mutations. J. Am. Chem. Soc. 2012, 134, 14099-14107.

[18] Greeneltch, N. G.; Blaber, M. G.; Henry, A. I.; Schatz, G. C.; Van Duyne, R. P. Immobilized Nanorod Assemblies: Fabrication and Understanding of Large Area SurfaceEnhanced Raman Spectroscopy Substrates. Anal. Chem. 2013, 85, 2297-2303.

[19] Zhang, Q. B.; Xie, J. P.; Yu, Y.; Lee, J. Y. Monodispersity control in the synthesis of monometallic and bimetallic quasi-spherical gold and silver nanoparticles. Nanoscale 2010, 2, 1962-1975.

[20] Brust, M.; Walker, M.; Bethell, D.; Schiffrin, D. J.; Whyman, R. Synthesis of thiolderivatized gold nanoparticles in a 2-phase liquid-liquid system. J. Chem. Soc., Chem. Commun. 1994, 10.1039/c39940000801, 801-802.

[21] Korgel, B. A.; Fullam, S.; Connolly, S.; Fitzmaurice, D. Assembly and self-organization of silver nanocrystal superlattices: Ordered "soft spheres". J. Phys. Chem. B 1998, 102, 8379-8388.

[22] Zheng, N.; Fan, J.; Stucky, G. D. One-step one-phase synthesis of monodisperse noblemetallic nanoparticles and their colloidal crystals. J. Am. Chem. Soc. 2006, 128, 65506551.

[23] Courty, A.; Lisiecki, I.; Pileni, M. P. Vibration of self-organized silver nanocrystals. $J$. Chem. Phys. 2002, 116, 8074-8078.

[24] Peng, S.; McMahon, J. M.; Schatz, G. C.; Gray, S. K.; Sun, Y. G. Reversing the sizedependence of surface plasmon resonances. Proc. Natl. Acad. Sci. U. S. A. 2010, 107, $14530-14534$.

[25] Wiley, B.; Sun, Y. G.; Xia, Y. N. Synthesis of silver nanostructures with controlled shapes and properties. Accounts Chem. Res. 2007, 40, 1067-1076.

[26] Garcia-Barrasa, J.; Lopez-de-Luzuriaga, J. M.; Monge, M.; Soulantica, K.; Viau, G. Synthesis of thiolate-protected silver nanocrystal superlattices from an organometallic precursor and formation of molecular di-n-alkyldisulfide lamellar phases. J. Nanopart. Res. 2011, 13, 791-801.

[27] Taleb, A.; Petit, C.; Pileni, M. P. Synthesis of highly monodisperse silver nanoparticles from AOT reverse micelles: A way to 2D and 3D self-organization. Chem. Mat. 1997, 9, 950-959.

[28] Huang, Z. L.; Meng, G. W.; Huang, Q.; Chen, B.; Zhou, F.; Hu, X. Y.; Qian, Y. W.; Tang, H. B.; Han, F. M.; Chu, Z. Q. Polyacrylic acid sodium salt film entrapped Ag-nanocubes as molecule traps for SERS detection. Nano Res. 2014, 7, 1177-1187.

[29] Ling, X. Y.; Yan, R. X.; Lo, S.; Hoang, D. T.; Liu, C.; Fardy, M. A.; Khan, S. B.; Asiri, A. M.; Bawaked, S. M.; Yang, P. D. Alumina-coated Ag nanocrystal monolayers as surfaceenhanced Raman spectroscopy platforms for the direct spectroscopic detection of water splitting reaction intermediates. Nano Res. 2014, 7, 132-143.

[30] Wustholz, K. L.; Henry, A. I.; McMahon, J. M.; Freeman, R. G.; Valley, N.; Piotti, M. E.; Natan, M. J.; Schatz, G. C.; Van Duyne, R. P. Structure-Activity Relationships in Gold Nanoparticle Dimers and Trimers for Surface-Enhanced Raman Spectroscopy. J. Am. Chem. Soc. 2010, 132, 10903-10910. 
[31] Le Ru, E. C.; Grand, J.; Sow, I.; Somerville, W. R. C.; Etchegoin, P. G.; TreguerDelapierre, M.; Charron, G.; Felidj, N.; Levi, G.; Aubard, J. A Scheme for Detecting Every Single Target Molecule with Surface-Enhanced Raman Spectroscopy. Nano Lett. 2011, 11, 5013-5019.

[32] Cecchini, M. P.; Turek, V. A.; Paget, J.; Kornyshev, A. A.; Edel, J. B. Self-assembled nanoparticle arrays for multiphase trace analyte detection. Nat. Mater. 2013, 12, 165-171.

[33] Alvarez-Puebla, R. A.; Agarwal, A.; Manna, P.; Khanal, B. P.; Aldeanueva-Potel, P.; Carbo-Argibay, E.; Pazos-Perez, N.; Vigderman, L.; Zubarev, E. R.; Kotov, N. A.; LizMarzan, L. M. Gold nanorods 3D-supercrystals as surface enhanced Raman scattering spectroscopy substrates for the rapid detection of scrambled prions. Proc. Natl. Acad. Sci. U. S. A. 2011, 108, 8157-8161.

[34] Pazos-Perez, N.; Wagner, C. S.; Romo-Herrera, J. M.; Liz-Marzan, L. M.; de Abajo, F. J. G.; Wittemann, A.; Fery, A.; Alvarez-Puebla, R. A. Organized Plasmonic Clusters with High Coordination Number and Extraordinary Enhancement in Surface-Enhanced Raman Scattering (SERS). Angew. Chem., Int. Edit. 2012, 51, 12688-12693.

[35] Li, J. F.; Huang, Y. F.; Ding, Y.; Yang, Z. L.; Li, S. B.; Zhou, X. S.; Fan, F. R.; Zhang, W.; Zhou, Z. Y.; Wu, D. Y.; Ren, B.; Wang, Z. L.; Tian, Z. Q. Shell-isolated nanoparticleenhanced Raman spectroscopy. Nature 2010, 464, 392-395.

[36] Taleb, A.; Petit, C.; Pileni, M. P. Optical properties of self-assembled 2D and 3D superlattices of silver nanoparticles. J. Phys. Chem. B 1998, 102, 2214-2220.

[37] Andrieux-Ledier, A.; Tremblay, B.; Courty, A. Stability of Self-Ordered Thiol-Coated Silver Nanoparticles: Oxidative Environment Effects. Langmuir 2013, 29, 13140-13145.

[38] Sutter, E.; Jungjohann, K.; Bliznakov, S.; Courty, A.; Maisonhaute, E.; Tenney, S.; Sutter, P. In situ liquid-cell electron microscopy of silver-palladium galvanic replacement reactions on silver nanoparticles. Nat. Commun. 2014, 5, 4946.

[39] Henry, A. I.; Courty, A.; Pileni, M. P.; Albouy, P. A.; Israelachvili, J. Tuning of solid phase in supracrystals made of silver nanocrystals. Nano Lett. 2008, 8, 2000-2005.

[40] Courty, A. Silver Nanocrystals: Self-Organization and Collective Properties. J. Phys. Chem. C 2010, 114, 3719-3731.

[41] Courty, A.; Richardi, J.; Albouy, P. A.; Pileni, M. P. How To Control the Crystalline Structure of Supracrystals of 5-nm Silver Nanocrystals. Chem. Mat. 2011, 23, 4186-4192.

[42] Courty, A.; Araspin, O.; Fermon, C.; Pileni, M. P. "Supracrystals" made of nanocrystals. 2. Growth on HOPG substrate. Langmuir 2001, 17, 1372-1380.

[43] Andrieux-Ledier, A.; Tremblay, B.; Courty, A. Synthesis of Silver Nanoparticles Using Different Silver Phosphine Precursors: Formation Mechanism and Size Control. J. Phys. Chem. C 2013, 117, 14850-14857.

[44] Dong, A. G.; Chen, J.; Vora, P. M.; Kikkawa, J. M.; Murray, C. B. Binary nanocrystal superlattice membranes self-assembled at the liquid-air interface. Nature 2010, 466, 474477.

[45] Bain, C. D.; Troughton, E. B.; Tao, Y. T.; Evall, J.; Whitesides, G. M.; Nuzzo, R. G. Formation of monolayer films by the spontaneous assembly of organic thiols from solution onto gold. J. Am. Chem. Soc. 1989, 111, 321-335.

[46] Motte, L.; Billoudet, F.; Lacaze, E.; Douin, J.; Pileni, M. P. Self-organization into 2D and 3D superlattices of nanosized particles differing by their size. J. Phys. Chem. B 1997, 101, 138-144. 
[47] Kornyshev, A. A.; Marinescu, M.; Paget, J.; Urbakh, M. Reflection of light by metal nanoparticles at electrodes. Phys. Chem. Chem. Phys. 2012, 14, 1850-1859.

[48] Zhang, D. H.; Liu, X. H.; Wang, X. Formation and optical properties of silver superlattice using hydrazine hydrate as reducing agent. Microsyst. Technol. 2011, 17, 1293-1299.

[49] Yoon, B.; Luedtke, W. D.; Barnett, R. N.; Gao, J. P.; Desireddy, A.; Conn, B. E.; Bigioni, T.; Landman, U. Hydrogen-bonded structure and mechanical chiral response of a silver nanoparticle superlattice. Nat. Mater. 2014, 13, 807-811.

[50] Palik, E. D. Handbook of optical constants of solids; Academic Press: Orlando, 1985.

[51] Renault, C.; Andrieux, C. P.; Tucker, R. T.; Brett, M. J.; Balland, V.; Limoges, B. Unraveling the Mechanism of Catalytic Reduction of O-2 by Microperoxidase-11 Adsorbed within a Transparent 3D-Nanoporous ITO Film. J. Am. Chem. Soc. 2012, 134, 6834-6845.

[52] Vitale, R.; Lista, L.; Lau-Truong, S.; Tucker, R. T.; Brett, M. J.; Limoges, B.; Pavone, V.; Lombardi, A.; Balland, V. Spectroelectrochemistry of Fe-III- and Co-III-mimochrome VI artificial enzymes immobilized on mesoporous ITO electrodes. Chem. Commun. 2014, 50, 1894-1896.

[53] Lin, M. H.; Chen, H. Y.; Gwo, S. Layer-by-Layer Assembly of Three-Dimensional Colloidal Supercrystals with Tunable Plasmonic Properties. J. Am. Chem. Soc. 2010, 132, 11259-11263.

[54] Tomlin, S. G. Optical reflection and transmission formulae for thin films. J. Phys. D-Appl. Phys. 1968, 1, 1667-1671.

[55] Rakic, A. D. Algorithm for the determination of intrinsic optical constants of metal films. Applications to Aluminum. Appl. Opt. 1995, 34, 4755-4767.

[56] Hartland, G. V. Optical Studies of Dynamics in Noble Metal Nanostructures. Chem. Rev. 2011, 111, 3858-3887.

[57] Wormeester, H.; Henry, A. I.; Kooij, E. S.; Poelsema, B.; Pileni, M. P. Ellipsometric identification of collective optical properties of silver nanocrystal arrays. J. Chem. Phys. 2006, 124.

[58] Blaber, M. G.; Henry, A. I.; Bingham, J. M.; Schatz, G. C.; Van Duyne, R. P. LSPR Imaging of Silver Triangular Nanoprisms: Correlating Scattering with Structure Using Electrodynamics for Plasmon Lifetime Analysis. J. Phys. Chem. C 2012, 116, 393-403.

[59] Nelayah, J.; Kociak, M.; Stephan, O.; de Abajo, F. J. G.; Tence, M.; Henrard, L.; Taverna, D.; Pastoriza-Santos, I.; Liz-Marzan, L. M.; Colliex, C. Mapping surface plasmons on a single metallic nanoparticle. Nat. Phys. 2007, 3, 348-353.

[60] Bryant, M. A.; Pemberton, J. E. Surface Raman-Scattering of self-assembled monolayers formed from 1-alkanethiols at Ag. J. Am. Chem. Soc. 1991, 113, 3629-3637.

[61] Levin, C. S.; Janesko, B. G.; Bardhan, R.; Scuseria, G. E.; Hartgerink, J. D.; Halas, N. J. Chain-length-dependent vibrational resonances in alkanethiol self-assembled monolayers observed on plasmonic nanoparticle substrates. Nano Lett. 2006, 6, 2617-2621.

[62] Lal, S.; Grady, N. K.; Goodrich, G. P.; Halas, N. J. Profiling the near field of a plasmonic nanoparticle with Raman-based molecular rulers. Nano Lett. 2006, 6, 2338-2343.

[63] Kleinman, S. L.; Sharma, B.; Blaber, M. G.; Henry, A. I.; Valley, N.; Freeman, R. G.; Natan, M. J.; Schatz, G. C.; Van Duyne, R. P. Structure Enhancement Factor Relationships in Single Gold Nanoantennas by Surface-Enhanced Raman Excitation Spectroscopy. J. Am. Chem. Soc. 2013, 135, 301-308. 
[64] Fontana, J.; Livenere, J.; Bezares, F. J.; Caldwell, J. D.; Rendell, R.; Ratna, B. R. Large surface-enhanced Raman scattering from self-assembled gold nanosphere monolayers. Appl. Phys. Lett. 2013, 102.

[65] Gui, J. Y.; Stern, D. A.; Frank, D. G.; Lu, F.; Zapien, D. C.; Hubbard, A. T. Adsorption and surface structural chemistry of thiophenol, benzyl mercaptan and alkyl mercaptans Comparative studies ar $\operatorname{Ag}(111)$ and $\operatorname{Pt}(111)$ electrodes by means of Auger Spectroscopy, electron-energy loss spectroscopy, low-energy electron diffraction and electrochemistry. Langmuir 1991, 7, 955-963.

[66] Fortgang, P.; Maisonhaute, E.; Amatore, C.; Delavaux-Nicot, B.; Iehl, J.; Nierengarten, J. F. Molecular Motion Inside an Adsorbed 5:1 Fullerene Hexaadduct Observed by Ultrafast Cyclic Voltammetry. Angew. Chem., Int. Ed. 2011, 50, 2364-2367.

[67] Amatore, C.; Genovese, D.; Maisonhaute, E.; Raouafi, N.; Schöllhorn, B. Electrochemically driven release of picomole amounts of calcium ions with temporal and spatial resolution. Angew. Chem., Int. Ed. 2008, 47, 5211-5214.

[68] Chazalviel, J. N.; Allongue, P. On the Origin of the Efficient Nanoparticle Mediated Electron Transfer across a Self-Assembled Monolayer. J. Am. Chem. Soc. 2011, 133, 762764.

[69] Amatore, C.; Genovese, D.; Maisonhaute, E.; Raouafi, N.; Schoellhorn, B. Electrochemically driven release of picomole amounts of calcium ions with temporal and spatial resolution. Angew. Chem., Int. Ed. 2008, 47, 5211-5214.

[70] Liu, H. L.; Yang, Z. L.; Meng, L. Y.; Sun, Y. D.; Wang, J.; Yang, L. B.; Liu, J. H.; Tian, Z. Q. Three-Dimensional and Time-Ordered Surface-Enhanced Raman Scattering Hotspot Matrix. J. Am. Chem. Soc. 2014, 136, 5332-5341. 